\title{
Effects of temperature and incubation time on the in vitro expression of proteases, phospholipases, lipases and DNases by different species of Trichosporon
}

\author{
Henri Donnarumma Levy Bentubo ${ }^{1 *}$ and Olga Fischman Gompertz ${ }^{2}$
}

\begin{abstract}
Fungi produce a broad spectrum of enzymes capable of degrading different substrates in nature. When the substrate is the tissue of a vertebrate host, these enzymes acts as a fungal virulence factor that increases the pathogenicity of the fungus. Trichosporon yeasts are emerging pathogens that infect immunocompromised patients. Little is known about the virulence characteristics of these fungi. The aim of this research was to characterize the behavior of protease, phospholipase, lipase and DNase production in different species of Trichosporon, with a focus on the influence of incubation temperature on the expression of these enzymes. Classical methodologies were used in all of the experiments, and the results were statistically analyzed. The proportions of the samples that produced each type of enzyme were as follows: lipases (95.5\%), phospholipases (56.8\%), proteases (50,0\%) and DNases (38.6\%). The incubation temperature was an important factor in the expression of enzymatic activity, and it influenced the incubation period of each species. Although these data concerning the enzymatic activity expressed by isolates of Trichosporon are valuable, further research is warranted to completely characterize this new pathogen, as well as in vivo studies to determine the roles of these enzymes in the pathogenesis of trichosporonosis.
\end{abstract}

Keywords: Proteases; Phospholipases; Lipases; DNases; Trichosporon spp; Virulence factors

\section{Background}

Virulence factors allow pathogenic agents to grow and establish themselves in host tissues. Dimorphism, thermotolerance, the expression of cell wall components, the presence of a capsule and the secretion of enzymes are all major effects of virulence factors identified in fungi (Naglik et al. 2004; Jain et al. 2008; Colombo et al. 2011). Fungi express a broad spectrum of enzymes capable of degrading various components of host tissues. The study of extracellular enzymatic activity has contributed to the understanding of some of the ecological characteristics of pathogenic yeasts and molds (Gácser et al. 2007). Extracellular enzyme activity is well studied in Candida yeasts, but little is known about members of the phylum Basidiomycota, such as the genus Trichosporon (Coutinho and Paula 2000; Naglik et al.

\footnotetext{
* Correspondence: hbentubo@yahoo.com.br

'Institute of Health Sciences, Universidade Cruzeiro do Sul, Rua Doutor Ussiel Cirilo, 225, Zip Code: 08060-070 São Paulo, SP, Brazil

Full list of author information is available at the end of the article
}

2004; Ichikawa et al. 2004). Although Trichosporon spp. represent the third most common yeast responsible for invasive fungal infections, few published studies have characterized the virulence of this fungus (Pagano et al. 2006; Chagas-Neto et al. 2008).

The genus Trichosporon is associated with superficial infections, such as white piedra or onychomycosis, which can serve as reservoirs for invasive infection. Trichosporonosis is the name assigned to the invasive form of the diseases caused by Trichosporon spp.. Malignant hematological diseases, such as leukemias and lymphomas, and organ transplantation, especially bone marrow transplantation, cause patients to become more prone to trichosporonosis due to the profound immune depression associated with those conditions (ChagasNeto et al. 2008). Most cases of Trichosporon infection are reported in medical centers in North America (33.9\%), Europe (27.6\%) and Asia (23.3\%) (Menezes et al. 2012). Mortality rates can reach $80 \%$, even after 

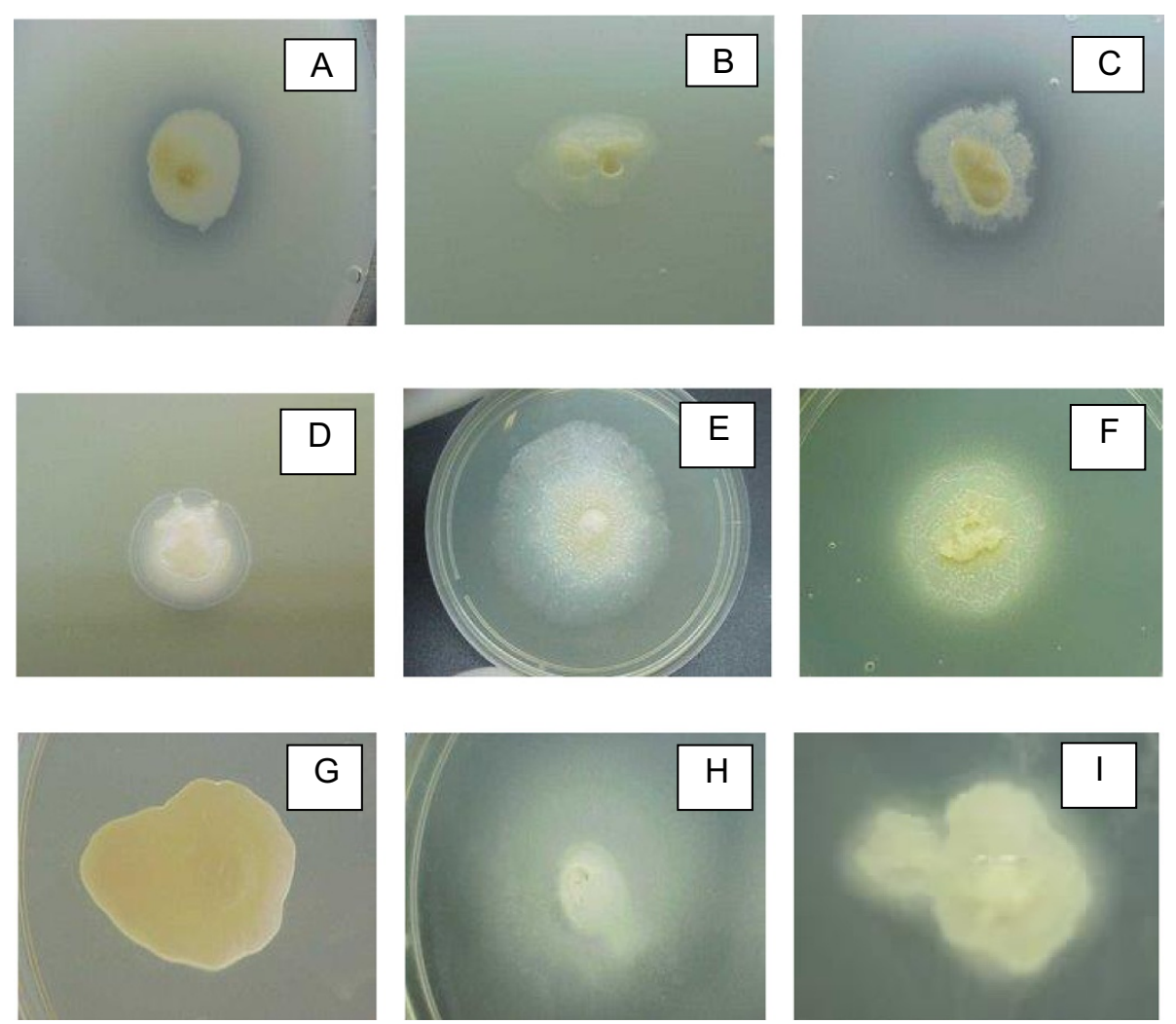

Figure 1 Expression of extracellular enzyme activity by $\mathbf{4 4}$ samples Trichosporon spp. In the first line: activity of protease in C. albicans (ICB 12A) (A) T. asahii (ICB 439/98) not producing (B) and a positive strain of T. inkin (CBS 5585) (C). The second line shows a positive sample for production of phospholipase (D) and negative samples (E) and positive (F) to lipase, respectively. In G, note the absence of halo of degradation by DNase (G) and two other producers samples DNAse in $\mathbf{H}$ and $\mathbf{I}$.

the initiation of antifungal therapy (Nucci et al. 2010; Colombo et al. 2011).

The disseminated form of trichosporonosis is characterized by a nonspecific fever that does not yield to conventional antibiotic therapy. The infection progresses rapidly, culminating in multiple organ failure. The lungs and kidneys become overwhelmed. Patients with pulmonary involvement have dyspnea and cough, sometimes with blood. Renal failure manifests as hematuria and proteinuria (Heslop et al. 2011). The involvement of the skin is characterized by erythematous papules on the trunk and extremities, which may develop blisters with necrotic centers (Walsh et al. 1993; Hsiao et al. 1994). Histopathological findings from experimental animal infections and cases of human infection have shown that the lesions of trichosporonosis are due to embolisms produced by the vascular invasion of the fungus. Therefore, multifocal areas of infarction are also observed in the affected organs (Nahass et al. 1993; Chagas-Neto et al. 2008).

Currently, 50 Trichosporon species are recognized, 16 of which are considered etiological agents of infection: Trichosporon asahii, T. asteroides, T. coremiiforme, T. cutaneum, T. chiarelli, T. dermatis, T. dohaense, T. domesticum,
T. faecale, T. inkin, T. japonicum, T. jirovecii, T. lactis, T. montevideense, T. mucoides and T. ovoides (Pagnocca et al. 2010; Colombo et al. 2011). Trichosporon species isolated from clinical samples are associated with specific types of infection. T. inkin and T. ovoides are common agents of white piedra of the pubic hair and scalp, respectively, whereas $T$. asteroides and T. cutaneum are associated with lesions of the skin and nails (Chagas-Neto et al. 2008). T. asahii is the species most frequently associated with invasive infections, followed by $T$. mucoides and T. inkin (Fleming et al. 2002; Madariaga et al. 2003). The objective of this research was to investigate the influence of

Table 1 General profile of 44 samples of Trichosporon spp. production of extracellular enzymes

\begin{tabular}{|c|c|c|c|c|c|c|c|c|}
\hline \multirow{2}{*}{$\begin{array}{l}\text { Sample } \\
\text { profile }\end{array}$} & \multicolumn{2}{|c|}{ Proteinase } & \multicolumn{2}{|c|}{ Fosfolipase } & \multicolumn{2}{|c|}{ Lipase } & \multicolumn{2}{|c|}{ DNAse } \\
\hline & $\mathrm{N}$ & (\%) & $\mathrm{N}$ & (\%) & $\mathrm{N}$ & $(\%)$ & $\mathrm{N}$ & (\%) \\
\hline$(-)$ & 22 & $(50,0)$ & 19 & $(43,2)$ & 2 & $(4,5)$ & 27 & $\overline{(61,4)}$ \\
\hline$(+)$ & 22 & $(50,0)$ & 25 & $(56,8)$ & 42 & $(95,5)$ & 17 & $(38,6)$ \\
\hline$(++)$ & 9 & $(40,9)$ & 6 & $(24,0)$ & 30 & $(71,4)$ & 10 & $(58,8)$ \\
\hline
\end{tabular}

$(-)=$ Negative samples, $(+)=$ samples that expressed enzyme activity and $(++)=$ samples considered strongly positive. Were considered the best temperature and time of reading for enzyme expression. 


\begin{tabular}{|c|c|c|c|c|}
\hline \multirow{2}{*}{$\begin{array}{c}\text { Day } \\
\text { reading }\end{array}$} & \multicolumn{2}{|c|}{$25^{\circ} \mathrm{C}$} & \multicolumn{2}{c|}{$37^{\circ} \mathrm{C}$} \\
\cline { 2 - 5 } & Mean & SEM $^{*}$ & Mean & SEM \\
\hline $\mathbf{1}$ & 1,000 & 0,000 & 1,000 & 0,000 \\
\hline $\mathbf{2}$ & 0,980 & 0,050 & 0,980 & 0,060 \\
\hline $\mathbf{3}$ & 0,950 & 0,014 & $0,920^{*}$ & 0,013 \\
\hline $\mathbf{5}$ & $0,940^{*}$ & 0,016 & 0,920 & 0,013 \\
\hline $\mathbf{7}$ & 0,950 & 0,011 & 0,930 & 0,012 \\
\hline $\mathbf{1 5}$ & 0,960 & 0,080 & 0,920 & 0,011 \\
\hline
\end{tabular}

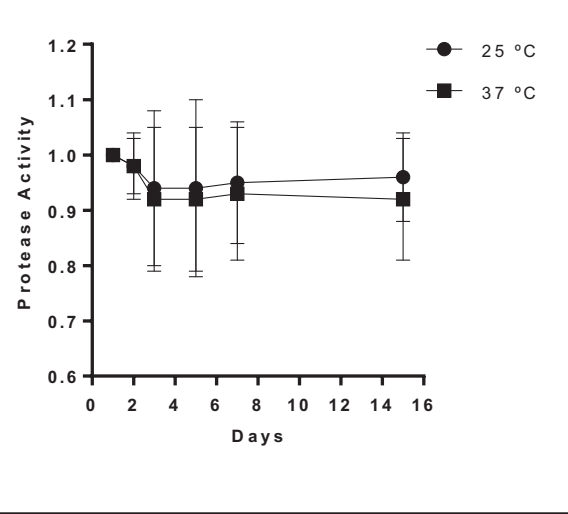

Figure 2 Mean values and standard error of protease activity in isolates of Trichosporon spp. Profile of expression of protease by Trichosporon spp. over 15 days of incubation; each point on the graph corresponds to the enzyme production rate observed in the $1 \mathrm{st}$, 2nd, 3rd, 5th, 7th and 15th days of incubation under two different temperatures, respectively. *Index "optimum" temperature for enzyme production $(P<0.0001$ vs Time 1$)$ over the time. \# SEM $=$ standard error of the mean.

temperature on the kinetics of the expression of proteases, phospholipases, lipases and DNases by different species of Trichosporon and to establish laboratory parameters for this emerging opportunistic yeast.

\section{Results}

Of the forty-four isolates of Trichosporon spp. analyzed, 22 (50\%) exhibited protease activity. This activity was strongly positive in approximately $41 \%$ of these 22 samples. Phospholipase activity was observed in $56.8 \%$ of the samples, with $25 \%$ of them categorized as strongly positive. Almost all (95.5\%) the isolates of Trichosporon spp. exhibited lipase activity, and $71 \%$ of them were strongly positive. DNase activity was detected in 17 isolates, and more than half (58.8\%) were strongly positive. The enzyme activity of samples of Trichosporon spp. is presented in Figure 1 and in Table 1. A significant difference between enzyme expression levels at room temperature and at $37^{\circ} \mathrm{C}$ was observed for proteases $(p<0.0001)$, phospholipases $(p<0.0012)$, lipases $(p<0.0001)$ and DNases $(p<0.0002)$. The higher temperature favored the expression of proteases and phospholipases. The activity of these enzymes was detected in representative numbers of isolates after three and five days of incubation, respectively. Incubation at room temperature $\left(25^{\circ} \mathrm{C}\right)$ produced a noticeable delay in the expression of proteases. Furthermore, there was a significant difference between the temperatures in the expression of phospholipases on the second day of incubation $(p<0.0012)$. Room temperature was found to be ideal for the expression of lipase and DNase. When the days of incubation were compared, we observed differences in the amount of lipase $(p<$ $0.0001)$ and DNAse $(p<0.0002)$ expression on the third

\begin{tabular}{|c|c|c|c|c|}
\hline \multirow{2}{*}{$\begin{array}{c}\text { Day } \\
\text { Reading }\end{array}$} & \multicolumn{2}{|c|}{$25^{\circ} \mathrm{C}$} & \multicolumn{2}{c|}{$37^{\circ} \mathrm{C}$} \\
\cline { 2 - 5 } & Mean & SEM $^{\#}$ & Mean & SEM \\
\hline $\mathbf{1}$ & 1,000 & 0,000 & 1,000 & 0,000 \\
\hline $\mathbf{2}$ & 1,000 & 0,000 & $0,970^{*}$ & 0,010 \\
\hline $\mathbf{3}$ & 0,980 & 0,070 & $0,890^{*}$ & 0,016 \\
\hline $\mathbf{5}$ & 0,970 & 0,011 & 0,890 & 0,14 \\
\hline $\mathbf{7}$ & 0,980 & 0,080 & 0,890 & 0,013 \\
\hline $\mathbf{1 5}$ & 0,980 & 0,070 & 0,940 & 0,011 \\
\hline
\end{tabular}

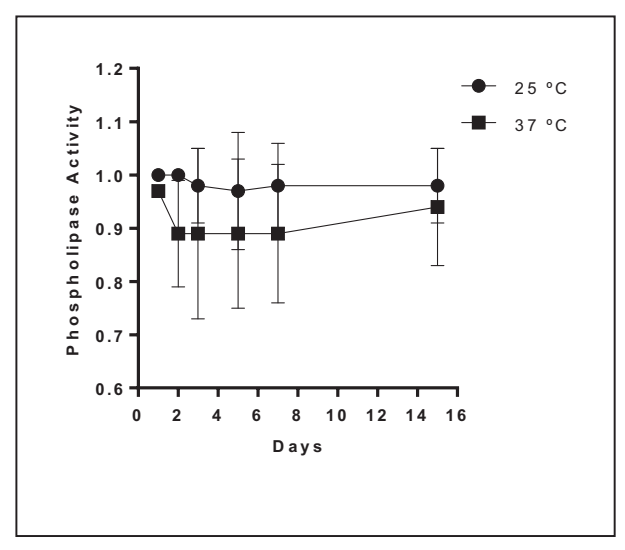

Figure 3 Mean values and standard error of phospholipase activity in isolates of Trichosporon spp. Profile of the expression of phospholipase by Trichosporon spp. over 15 days of observation; each point on the graph corresponds to the enzyme production rate observed in the 1st, 2nd, 3rd, 5th, 7th and 15th days of incubation under two different temperatures, respectively. *Index "optimum" temperature for enzyme production ( $p<0.0012$ vs. Time 1 ) over the time. \# SEM = standard deviation of the mean. 


\begin{tabular}{|c|c|c|c|c|}
\hline \multirow{2}{*}{$\begin{array}{c}\text { Day } \\
\text { Reading }\end{array}$} & \multicolumn{2}{|c|}{$25^{\circ} \mathbf{C}$} & \multicolumn{2}{c|}{$37^{\circ} \mathbf{C}$} \\
\cline { 2 - 5 } & Mean & SEM $^{\#}$ & Mean & SEM \\
\hline $\mathbf{1}$ & 1,000 & 0,000 & 1,000 & 0,000 \\
\hline $\mathbf{2}$ & 0,900 & 0,020 & 1,000 & 0,000 \\
\hline $\mathbf{3}$ & $0,800^{*}$ & 0,020 & 0,900 & 0,010 \\
\hline $\mathbf{5}$ & $0,700^{*}$ & 0,020 & $0,800^{*}$ & 0,020 \\
\hline $\mathbf{7}$ & 0,700 & 0,020 & 0,800 & 0,020 \\
\hline $\mathbf{1 5}$ & 0,700 & 0,020 & $0,700^{*}$ & 0,020 \\
\hline
\end{tabular}

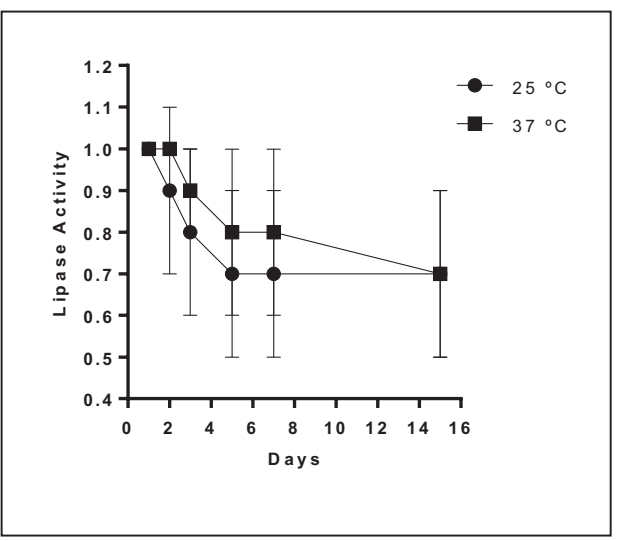

Figure 4 Mean values and standard error of lipase activity in isolates of Trichosporon spp. Profile of the expression of lipases by Trichosporon spp. over 15 days of observation; each point on the graph corresponds to the enzyme production rate observed in the 1st, 2nd, 3rd, 5 th, 7th and 15th days of incubation under two different temperatures, respectively. *Index "optimum" temperature for the enzyme production ( $p<0.0001$ vs. Time 1 and 2 ) over the time. \# SEM = standard error of the mean.

day of incubation compared with the previous days. The kinetics of enzyme expression in the 44 Trichosporon isolates are presented in Figures 2, 3, 4, 5.

When the species were analyzed separately, protease activity was detected in $66.7 \%(12 / 18)$ of $T$. asahii, $50 \%$ (5/10) of T. inkin and 50\% (2/4) T. mucoides and 25\% (3/12) of T. ovoides isolates. Strongly positive expression was evident in six of the T. asahii samples (33.3\%), two of T. ovoides (16.7\%) and one of T. inkin (10\%) (Table 2). Although protease activity in $T$. asahii has been detected both at $25^{\circ} \mathrm{C}$ and $37^{\circ} \mathrm{C}$, there was a significant difference between these temperatures $(p<0.0001)$. A large number of samples incubated at $37^{\circ} \mathrm{C}$ expressed protease activity on the third day, whereas activity was not detected until after five days when the samples were incubated at room temperature. Trichosporon inkin did not present enzyme activity when incubated under room temperature, preferring $37^{\circ} \mathrm{C}(p=0.0098)$. The incubation temperature did not affect the expression of this enzyme by isolates of $T$. mucoides $(p=0.6706)$ or T. ovoides $(p>0.9999)$, as shown in Figures $6,7,8,9$.

Phospholipase activity was positive in $33.3 \%(6 / 18)$ of the T. asahii, $60 \%(6 / 10)$ of the T. Inkin, 75\% (3/4) of the T. mucoides and $83.3 \%(10 / 12)$ of the T. ovoides isolates. Strongly positive enzyme activity was detected in $16.7 \%$ (3/18) of the T. asahii, $10 \%(1 / 10)$ of the T. inkin, $8.3 \%$ (1/12) of the T. ovoides and 25\% (1/4) of the T. mucoides isolates (Table 2). Incubation at $37^{\circ} \mathrm{C}$ significantly influenced

\begin{tabular}{|c|c|c|c|c|c|}
\hline \multirow{2}{*}{$\begin{array}{c}\text { Day } \\
\text { Reading }\end{array}$} & \multicolumn{2}{|c|}{$25^{\circ} \mathrm{C}$} & \multicolumn{2}{|c|}{$37^{\circ} \mathrm{C}$} & \multirow{8}{*}{ 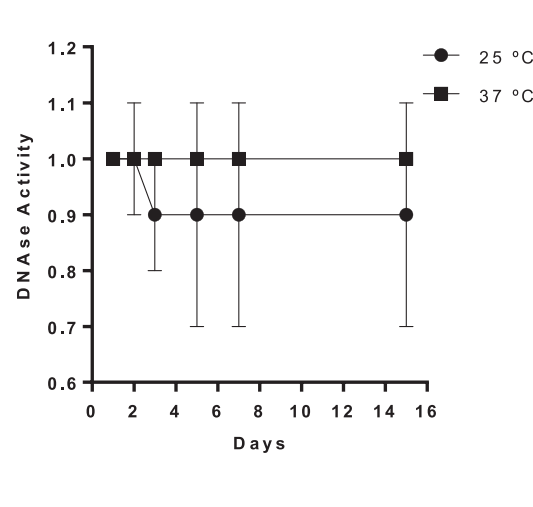 } \\
\hline & Mean & SEM $^{\#}$ & Mean & SEM & \\
\hline 1 & 1,000 & 0,000 & 1,000 & 0,000 & \\
\hline 2 & 1,000 & 0,010 & 1,000 & 0,000 & \\
\hline 3 & $0,900^{*}$ & 0,010 & 1,000 & 0,000 & \\
\hline 5 & 0,900 & 0,020 & 1,000 & 0,000 & \\
\hline 7 & 0,900 & 0,020 & 1,000 & 0,000 & \\
\hline 15 & 0,900 & 0,020 & 1,000 & 0,000 & \\
\hline
\end{tabular}

Figure 5 Mean values and standard error of the activity of DNase in isolates of Trichosporon spp. Profile of DNases production by Trichosporon spp. over 15 days of observation; each point on the graph corresponds to the enzyme production rate observed in the 1st, 2nd, 3rd, 5th, 7th and 15th days of incubation under two different temperatures, respectively. *Index "optimum" temperature for the enzyme production ( $p<0.0002$ vs. Time 1 and 2 ) over the time. \# SEM = standard error of the mean. 
Table 2 Expression of extracellular enzymes, in absolute numbers, expressed by different species: T. asahii (18), T. inkin (10), T. mucoides (4) and T. ovoides (12), regardless of the incubation temperature

\begin{tabular}{|c|c|c|c|c|c|c|c|c|c|c|c|c|}
\hline \multirow[t]{2}{*}{ Species } & \multicolumn{3}{|c|}{ Proteinase } & \multicolumn{3}{|c|}{ Fosfolipase } & \multicolumn{3}{|c|}{ Lipase } & \multicolumn{3}{|c|}{ DNAse } \\
\hline & $(-)$ & $(+)$ & $(++)$ & $(-)$ & $(+)$ & $(++)$ & $(-)$ & $(+)$ & $(++)$ & $(-)$ & $(+)$ & $(++)$ \\
\hline T. asahii & 6 & 12 & 6 & 12 & 6 & 3 & 0 & 18 & 10 & 10 & 8 & 2 \\
\hline T. inkin & 5 & 5 & 1 & 4 & 6 & 1 & 1 & 9 & 7 & 3 & 7 & 7 \\
\hline T. mucoides & 2 & 2 & 0 & 1 & 3 & 1 & 1 & 3 & 2 & 4 & 0 & 0 \\
\hline T. ovoides & 9 & 3 & 2 & 2 & 10 & 1 & 0 & 12 & 11 & 10 & 2 & 1 \\
\hline Total & 22 & 22 & 9 & 19 & 25 & 6 & 2 & 42 & 30 & 27 & 17 & 10 \\
\hline
\end{tabular}

$(-)=$ Negative samples, $(+)=$ samples that expressed enzyme activity and $(++)=$ samples considered strongly positive. Were considered the best temperature and time of reading for enzyme expression.

the expression of phospholipases in T. asahii $(p<0.0001)$, T. inkin $(p<0.0001)$ and T. ovoides $(p=0.0093)$. There was no significant difference between the two incubation temperatures for the expression of phospholipases in T. mucoides $(p=0.1957)$. A significant number of T. asahii (6/18), T. inkin (6/10) and T. ovoides isolates $(9 / 12)$ expressed enzymatic activity on the fifth day of incubation, whereas activity was detected at three days in the isolates of T. mucoides. A statistical analysis revealed a significant difference in the expression of phospholipases after three days of incubation among T. asahii, T. inkin, and T. ovoides (Figures 6, 7, 8, 9).

Forty-two (95.45\%) samples of Trichosporon spp. exhibited lipase activity. All the isolates of T. asahii (18/18) and $T$. ovoides (12/12) showed positive lipase activity. T. inkin and T. mucoides were positive in 90\% (9/10) and $75 \%(3 / 4)$ of the samples, respectively (Table 2$)$. The following percentages of the samples of the examined species
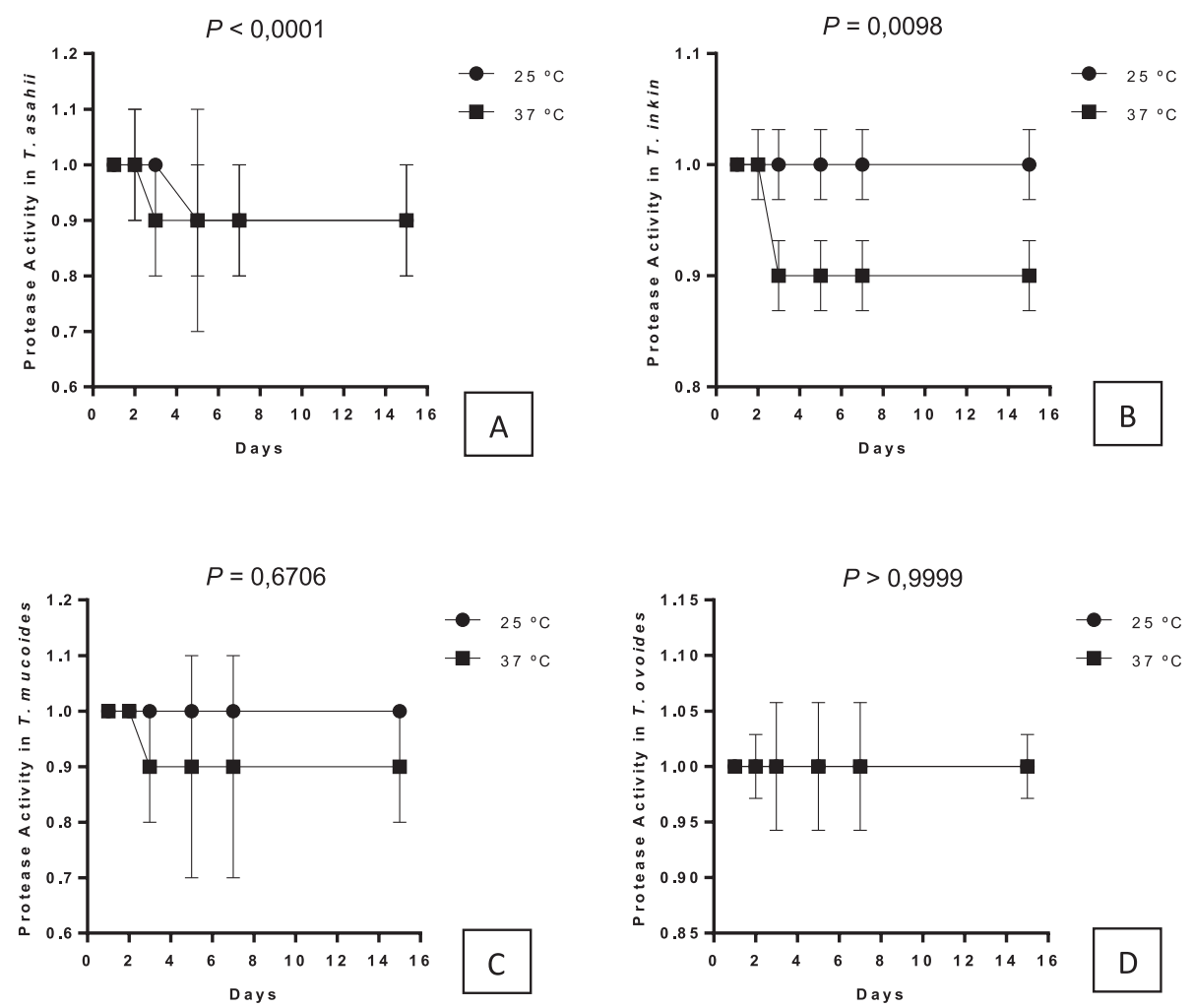

Figure 6 Protease expression by different species of the yeasts of the genus Trichosporon over 15 days of incubation at different temperatures; each point on the graph corresponds to the average rate of enzyme production seen in the $1 \mathrm{st}$, 2nd, 3rd, 5th, 7th and 15th days of observation, respectively. The profiles of T. asahii (A) T. inkin (B) T. mucoides (C) and T ovoides (D). The $P$ value represents a statistically significant difference between the two incubation temperatures over time. 

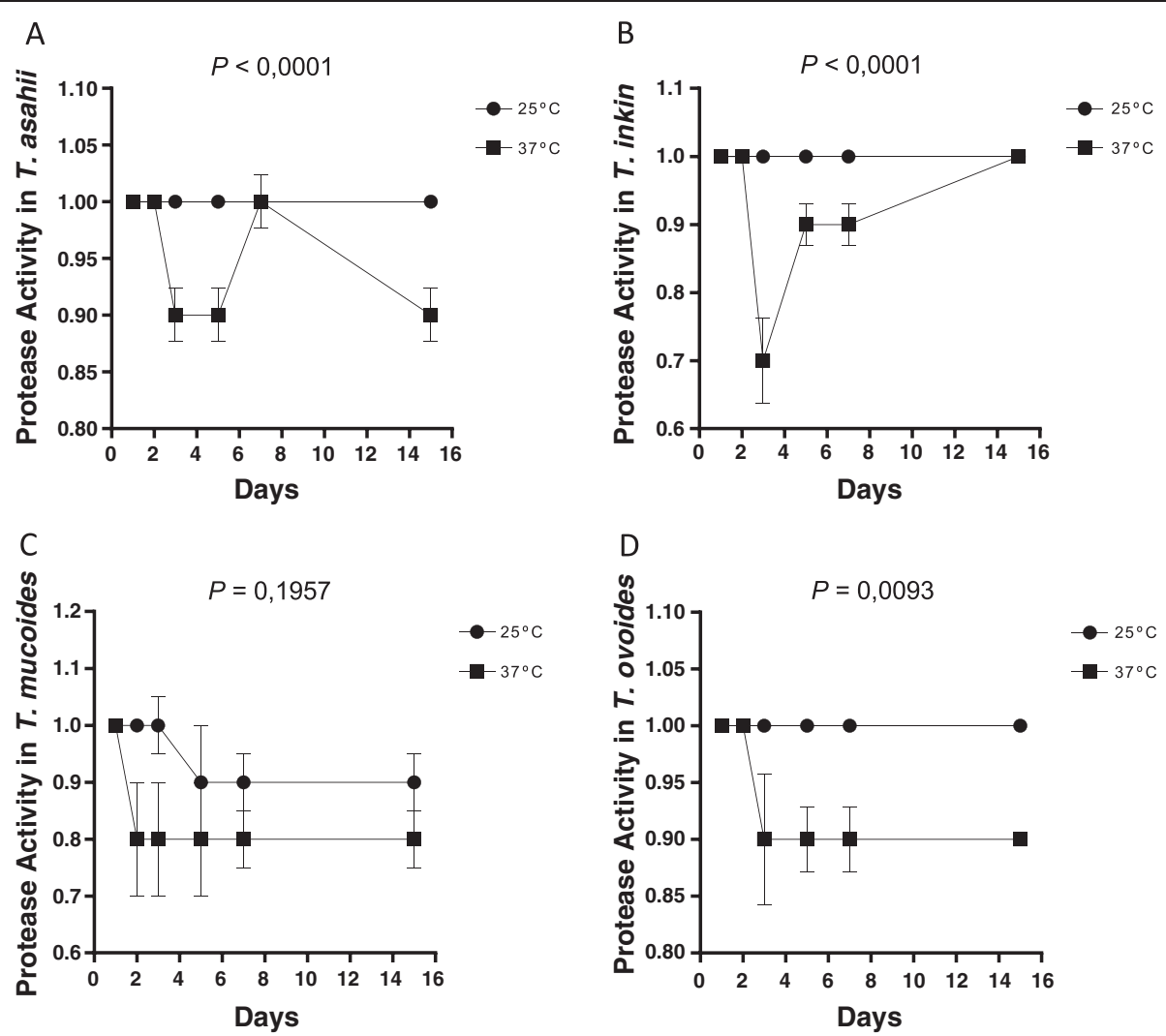

Figure 7 Phospholipase expression by different species of the yeasts of the genus Trichosporon over 15 days of incubation at different temperatures; each point on the graph corresponds to the average rate of enzyme production seen in the $1 \mathrm{st}, 2 \mathrm{nd}, 3 \mathrm{rd}, 5 \mathrm{th}, 7 \mathrm{th}$ and 15th days of observation, respectively. The profiles of T. asahii (A) T. inkin (B) T. mucoides (C) and T. ovoides (D). The $P$ value is a statistically significant difference between the two incubation temperatures over time.

were strongly positive: T. asahii, $55.5 \%$ (10/18); T. inkin, 70\% (7/10); T. mucoides, 50\% (2/4); and T. ovoides, 91.7\% (11/12). Significant numbers of samples of $T$. asahii (18/18) and $T$. ovoides (12/12) expressed lipase activity on the fifth day of incubation at room temperature. The samples of $T$. inkin and T. mucoides expressed this activity earlier, after three days of incubation, although incubation temperature produced no statistically significant effect on the expression of lipases in T. mucoides $(\mathrm{p}=0,0845)$ (Figures 6, 7, 8, 9).

T. asahii was positive for DNase activity in $44.4 \%$ (8/18) of the isolates, T. inkin [70\% (7/10)] and $T$. ovoides $[16.7 \%(2 / 12)]$ (Table 2). The same isolates showed strongly positive enzyme activity in $11.1 \%(2 / 18)$ of T. asahii, $70 \%(7 / 10)$ of $T$. inkin and $8.3 \%(1 / 12)$ of $T$. ovoides isolates. None of the isolates of T. mucoides showed DNase activity. A substantial number of the T. asahii samples (8/18) exhibited DNase activity after 7 days of incubation. In the isolates of T. inkin (7/10) and T. ovoides (2/12), DNase activity was observed after 5 days of incubation. In all cases, room temperature was found to be the most favorable temperature for the expression of DNase activity, except for T. mucoides isolates that did not express enzyme activity in either temperature (Figures 6, 7, 8, 9).

\section{Discussion}

Different populations of microorganisms that constitute the microbiota of humans, other animals and the environment adopt dynamic interactive mechanisms in response to competition to survive and evolve. In this context, the modulation of virulence mechanisms is essential to the development of opportunistic microorganisms (Tosta 2001). The close relationship between a parasite and its host sometimes drives adaptations in both organisms to promote their successful coexistence; in some cases, this process leads to the attenuation of virulence (Forattini 2001).

Virulence can be expressed through numerous mechanisms with the common goal of promoting the adhesion, penetration and multiplication of a parasite in the target tissue of its host (Forattini 2001). Studies of virulence in different species of pathogenic fungi have contributed to the understanding of the pathogenesis of the resulting infections. The expression of extracellular enzymes, such 

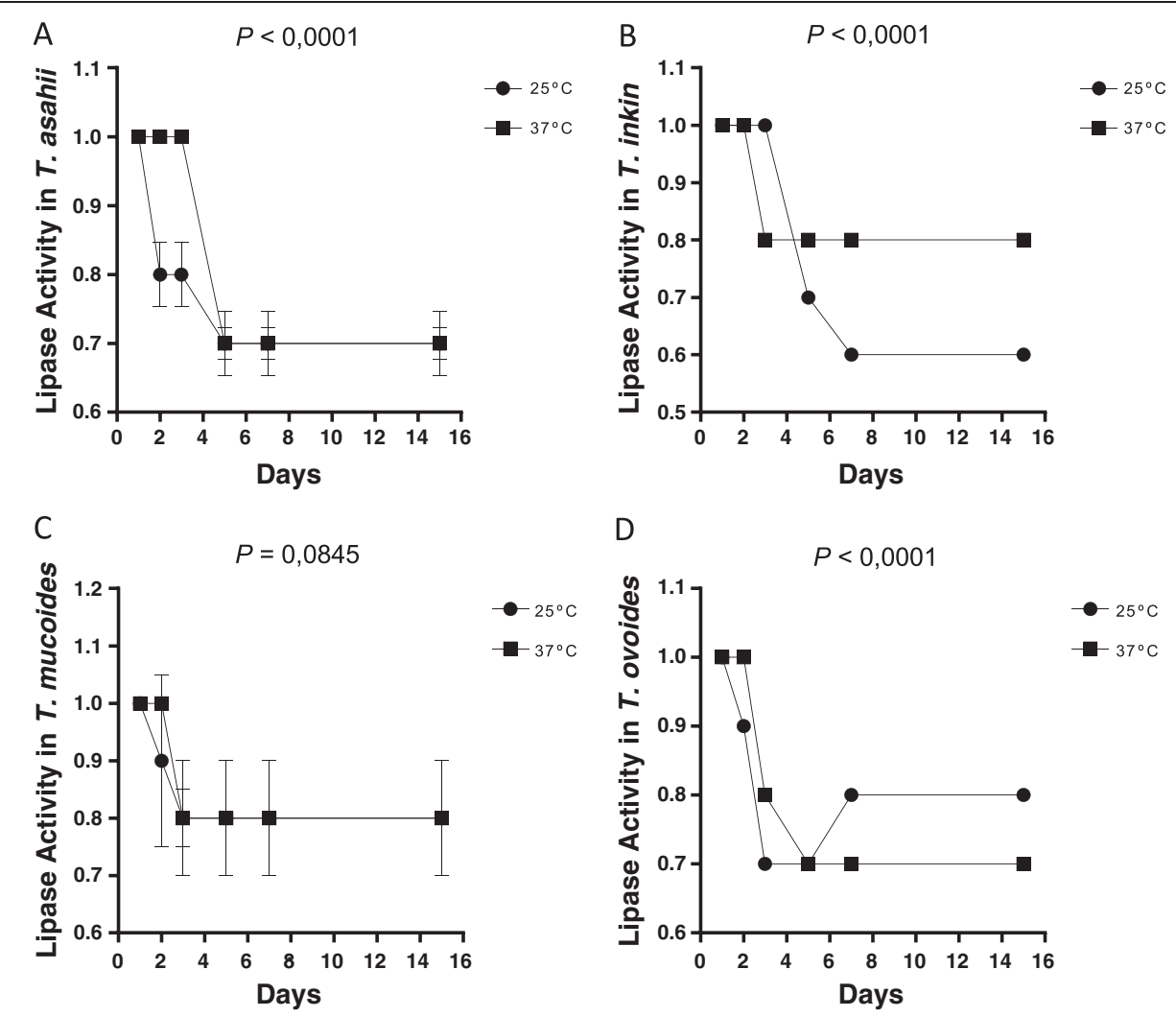

Figure 8 Lipase expression by different species of the yeasts of the genus Trichosporon over 15 days of incubation at different temperatures; each point on the graph corresponds to the average rate of enzyme production seen in the $1 \mathrm{st}, 2 \mathrm{nd}, 3 \mathrm{rd}, 5 \mathrm{th}, 7 \mathrm{th}$ and 15th days of observation, respectively. The profiles of T. asahii (A) T. inkin (B) T. mucoides (C) and T. ovoides (D). The $P$ value is a statistically significant difference between the two incubation temperatures over time.

as proteases, phospholipases, lipases and DNases, is associated with the virulence of strains that cause important mycoses, and the expression of these enzymes can provide clues about the nature of the relationship between the fungus and its host (Gácser et al. 2007).

The expression of extracellular enzymes has been increasingly studied in yeasts that are pathogenic to humans and other animals. Most of this work has been dedicated to the characterization of extracellular enzyme expression in the genus Candida, the most important yeast cause of nosocomial fungal infections. There are few published studies on the characteristics of enzymatic activity in Trichosporon spp. isolates (Ahearn et al. 1968; Teichert et al. 1989; Naglik et al. 2004). In the present study, exoenzymatic activity was detected in samples of $T$. asahii $(\mathrm{n}=18)$ T. inkin $(\mathrm{n}=10)$ T. mucoides $(\mathrm{n}=4)$ and T. ovoides $(n=12)$. The extracellular enzymatic activity displayed by the samples of Trichosporon spp. varied according to the enzyme studied. Lipase activity was observed in $95.5 \%$ of the isolates studied, whereas phospholipase, protease and DNase activity was detected in $56.8 \%, 50 \%$ and $38.6 \%$ of the samples, respectively.
Lipases are responsible for the hydrolysis of triglycerides and the consequent production of glycerides and free fatty acids; phospholipases act on phospholipids present in cell membranes. The findings obtained in this study suggest that lipases, including phospholipases, are the major enzymes produced by Trichosporon spp. The literature indicates that lipase is an important factor in the pathogenicity of Basidiomycetes, specifically Trichosporon and Malassezia yeasts (Ran et al. 1993). The activity of lipases, including phospholipases, in these yeasts has been reported in strains isolated from bovine milk in nature (Dharmsthiti and Ammaranond 1997; Gonzáles et al. 2001; Melville et al. 2011). In another study, lipase activity was detected in all 48 isolates of $T$. asahii from patients hospitalized in Turkey (Dag and Cerikçioglu 2006).

Proteases are extracellular enzymes produced by pathogens, which play an important role in overcoming host immunological barriers. Some sophisticated virulence mechanisms act through the induction of apoptotic pathways (Forattini 2001). Groninger and Eklund (1996) pioneered work in the characterization of the proteases produced by Trichosporon yeasts (Groninger and Eklund 

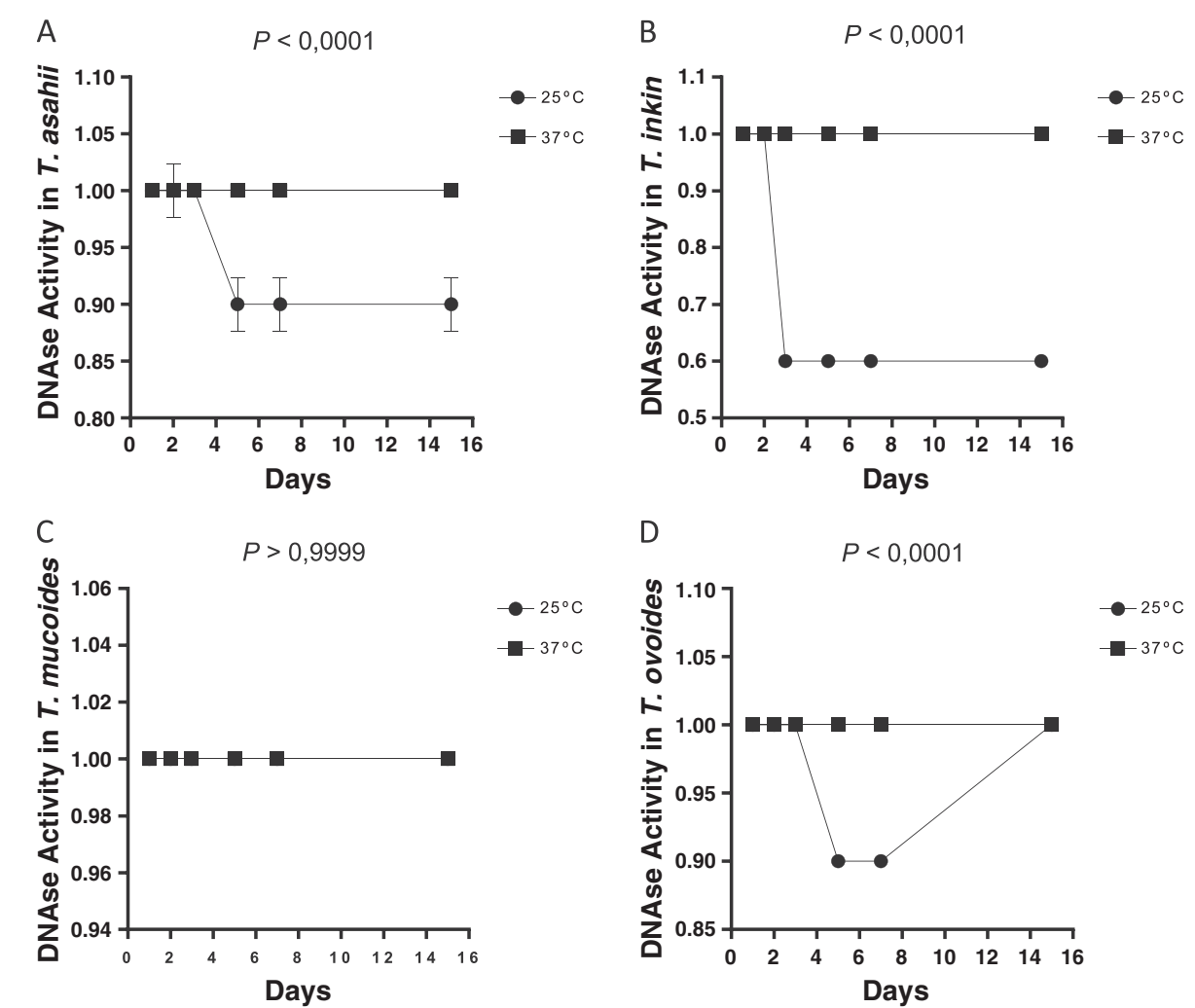

Figure 9 DNase expression by different species of the yeasts of the genus Trichosporon over 15 days of incubation at different temperatures; each point on the graph corresponds to the average rate of enzyme production seen in the $1 \mathrm{st}, 2 \mathrm{nd}, 3 \mathrm{rd}, 5 \mathrm{th}, 7 \mathrm{th}$ and 15th days of observation, respectively. The profiles of T. asahii (A) T. inkin (B) T. mucoides (C) and T. ovoides (D). The $P$ value is a statistically significant difference between the two incubation temperatures over time.

1996). In our study, 22 of the 44 tested Trichosporon isolates exhibited protease activity, and in $41 \%$ of the positive samples, this activity was strongly positive. However, a recent study reported that $T$. asahii isolates derived from both superficial and deep-seated infections did not express protease activity (Dag and Cerikçioglu 2006; Sun et al. 2012). These findings suggest that the protease expression profile of Trichosporon spp. is changing, reflecting the adaptation of pathogenic strains to their hosts. Deoxyribonucleases, also known as DNases, have received scant research attention in yeasts of the genus Trichosporon. Silvestre-Junior (2009) reported DNase activity in $84.3 \%$ of the Trichosporon isolates examined in a study conducted in Brazil. In the present study, only $38.6 \%$ of the samples were positive for DNase activity. The majority (58.8\%) of the isolates that exhibited DNase activity were classified as strongly positive. Our results disagree with those of Silvestre-Junior (2009), who observed strongly positive DNase activity in only 10.2\% of the samples (Silvestre-Junior 2009).

The induction of virulence mechanisms, such as the production of extracellular enzymes, is associated with factors related to the microorganism's physiological stability. These factors include temperature, which may be relevant for the production and expression of enzymatic activity, considering the mesophilic nature of most known pathogens. In our research, the enzymatic activity of proteases and phospholipases was more efficient when the samples were incubated at $37^{\circ} \mathrm{C}$ compared with incubation at $25^{\circ} \mathrm{C}$. Moreover, incubation at $37^{\circ} \mathrm{C}$ allowed the earlier detection of the expression of these enzymes (at $72 \mathrm{~h}$ ). Our findings concerning proteases disagree with those reported by Melville et al. (2011), who did not observe significant differences between the protease activity of yeasts (including Trichosporon spp.) incubated at both temperatures. However, our phospholipase results agree with those of these authors, who also observed the largest number of samples with enzyme expression at $37^{\circ} \mathrm{C}$ (Melville et al. 2011).

In the present study, lipase activity was detected in a larger number of Trichosporon spp. isolates during incubation at room temperature. Loperena et al. (2012) reported higher lipase activity in 31 yeasts isolated from different environments of the Antarctic continent when they were incubated at $20^{\circ} \mathrm{C}$ rather than at $4^{\circ} \mathrm{C}$. These findings suggest that the metabolic mechanisms of lipase production in yeasts are more independent of the substrate and the surrounding environment than previously assumed: both the mesophilic and the psychrophilic 
yeasts exhibited higher lipase expression when incubated at room temperature (Loperena et al. 2012).

Regardless of the enzyme in question, our results indicate that Trichosporon spp. have high growth potential at $37^{\circ} \mathrm{C}$, which is a factor associated with the virulence of infectious agents. In isolation, this factor may not be responsible for the opportunistic infections caused by yeasts of this genus; however, in combination with other factors, such as the production of proteases and phospholipases, the capacity to grow at body temperature is compelling (Melville et al. 2011). Despite the high mortality rates associated with trichosporonosis, the relevance of extracellular enzymes to these cases cannot be determined without performing in vivo experiments to better clarify the role of these enzymes in disease pathogenesis. Moreover, fungal virulence factors are not the only decisive contributor to the degree of mortality observed in immunocompromised patients infected with Trichosporon yeasts; patient outcomes result from a combination of several factors (Giorgio 1995; Zuben 1997; Forattini 2001).

\section{Conclusions}

Based on the results of this study, it can be concluded that there is a considerable predominance of lipases and phospholipases in the extracellular enzyme expression profiles of yeasts of the genus Trichosporon. The production of proteases and phospholipases is favored at $37^{\circ} \mathrm{C}$, whereas room temperature favors the expression of lipases and DNases. Although the limitation of relating the data in the paper to in vivo pathogenesis, may be the temperature of the human body can stimulates the early secretion of proteases and phospholipases, which can be detected after three days of incubation. The detection of strongly positive samples suggests that many of the Trichosporon species that are considered pathogenic are not yet fully adapted to their hosts; however, these species will undergo an attenuation of virulence and a relationship of increasingly harmonic parasitism in the future.

\section{Methods}

Forty-four samples of Trichosporon spp. were studied. The samples were classified in the collection as EPM001/2009 to EPM040/2012. Four strains were standard strains ( $T$. asahii CBS 2479, T. inkin CBS 5585, T. mucoides CBS 7625 , and T. ovoides CBS 7556), and the other 40 isolates were clinical samples maintained by periodic sampling in the Mycology Laboratory of the Departments of Cellular Biology and Microbiology, Immunology and Parasitology at the Federal University of São Paulo (UNIFESP). The isolates were previously identified by their phenotypic and genotypic profiles, as recommended by Rodriguez-Tudela et al. (2005). Cultures maintained in Sabouraud dextrose agar were used for all of the tests up to $72 \mathrm{~h}$. To standardize the enzymatic activity readings, tests were performed at 1, 2, 3, 5, 7 and 15 days of incubation. The enzymatic activity $(\mathrm{Pz})$ was determined by calculating the ratio of the diameter of the colony (dc) to the diameter of the halo produced (dcd). The results were classified as follows: negative $(\mathrm{Pz}=1.0)$, positive $(0.64 \leq \mathrm{Pz}<1.0)$ or strongly positive $(\mathrm{Pz}<0.64)$, as described by Price et al., 1982.

The enzyme activity assays followed the recommendations of Ruchel et al. (1982) for proteases, Price et al. (1982) for phospholipases, Muhsin et al. (1997) for lipases and López-Martínez et al. (1994) for DNases. The following substrates were used for the production of proteases, phospholipases, lipases and DNases: bovine serum albumin (fraction V, Sigma-Aldrich ${ }^{\mathrm{Tw}}$, St. Louis, MO, USA), homogenized egg yolk, Tween $20(20 \%)$ and DNase test agar (Oxoid $^{\mathrm{m}}$, Basingstoke, Hampishire, UK), respectively. A strain of Candida albicans (ICB-12A) was used as the positive control for the protease and phospholipase activity reactions. A strain of Malassezia pachydermatis (ICB-145) was the positive control for the lipase tests, and a strain of Staphylococcus aureus (ATCC 25923) was employed as a positive control for the DNase tests. Samples capable of producing a translucent halo (proteases), an opaque halo (phospholipases and lipases) or a halo of precipitate (DNases) were considered positive. All tests were performed in triplicate.

The statistical analyses were performed using the GraphPad Prism $^{\mathrm{Tm}}$ software, version 5.0. Student's $t$-test and Fisher's exact test were performed to compare the expression of enzyme activity at different times and temperatures. Significance was set at $p<0.05$.

\section{Competing interests}

The authors declare that they have no competing interests.

\section{Authors' contributions}

The HDLB contributed substantially to the acquisition of background data, the execution of the experiments, the analysis and interpretation of the results and the drafting of the manuscript. The OFG contributed to the conception and design of the study; they revised it critically for intellectual content and approved the final version for publication. Both authors read and approved the final manuscript.

\section{Authors' information}

This paper is part of the HDLB's thesis for the Postgraduate Program in Microbiology and Immunology of the Federal University of São Paulo (UNIFESP), São Paulo, SP, Brazil.

\section{Acknowledgements}

To National Council for Research and Scientific Development (CNPq) for financial support of this study.

\section{Author details}

${ }^{1}$ Institute of Health Sciences, Universidade Cruzeiro do Sul, Rua Doutor Ussiel Cirilo, 225, Zip Code: 08060-070 São Paulo, SP, Brazil. Department of Microbiology, Immunology and Parasitology, Federal University of São Paulo, Rua Botucatu, 862, Edifício das Ciências Biomédicas, 8th floor, Zip Code: 04060-064 São Paulo, SP, Brazil. 
Received: 23 March 2014 Accepted: 7 July 2014

Published: 26 July 2014

\section{References}

Ahearn DG, Meyers SP, Nichols RA (1968) Extracellular proteinases of yeasts and yeastlike fungi. Appl Microbiol 16:1370-1374

Chagas-Neto TC, Chaves GM, Colombo AL (2008) Update on the genus Trichosporon. Mycopathologia 166:121-132

Colombo AL, Padovan ACB, Chaves GM (2011) Current knowledge of Trichosporon spp. and tricosporonosis. Clin Microbiol Rev 24:682-700

Coutinho SD, Paula CR (2000) Proteinase, phospholipase, hyaluronidase and chondroitin-sulphatase production by Malassezia pachydermatis. Med Mycol 38:73-76

Dag A, Cerikçioglu N (2006) Investigation of some virulence factors of Trichosporon asahii strains isolated from the clinical samples of hospitalized patients. Mikrobiyol Bul 40:225-235

Dharmsthiti S, Ammaranond P (1997) Purification and characterization of lipase from a raw-milk yeast (Trichosporon asteroides). Biotechnol Appl Biochem 26:111-116

Fleming RV, Walsh TJ, Anaissie EJ (2002) Emerging and less common fungal pathogens. Infect Dis Clin North Am 16:915-933

Forattini OP (2001) O pensamento epidemiológico evolutivo sobre as infecções. Rev Saude Publica 36:257-262

Gácser A, Stehr F, Kröger C, Kredics L, Schäfer W, Nosanchuk JD (2007) Lipase 8 affects the pathogenesis of Candida albicans. Infect Immun 75:4710-4718

Giorgio S (1995) Moderna visão da evolução da virulência. Rev Saude Publica 29:398-402

Gonzáles RN, Wilson DJ, Sickles SA, Zurakowski MJ, Weybrecht PM (2001) Outbreaks of clinical mastitis caused by Trichosporon beigelli in dairy herds. JAVMA 218:238-242

Groninger HS, Eklund MW (1996) Characteristics of a proteinase of a Trichosporon species isolated from Dungeness crab meat. Appl Microbial 14:110-114

Heslop OD, Nyi MN, Abbott SP, Rainford LE, Castle DM, Coard KCM (2011) Disseminated trichosporonosis in a burn patient: meningitis and cerebral abscess due to Trichosporon asahii. J Clin Microbiol 49:4405-4408

Hsiao GH, Chang CC, Chen JC, Kuo WL, Huang SF (1994) Trichosporon beigelii fungemia with cutaneous dissemination. A case report and literature review. Acta Dermatol Venereol Stochk 74:481-482

Ichikawa T, Sugita T, Wang L, Yokoyama K, Nishimura K, Nishikawa A (2004) Phenotypic switching and $\beta$-N-Acetylhexosaminidase activity of the pathogenic yeast Trichosporon asahii. Microbiol Immunol 48:237-242

Jain N, Hasan F, Fries BC (2008) Phenotypic switching in fungi. Curr Fungal Infect Rep 2:180-188

Loperena L, Soria V, Varela H, Lupo S, Bergalli A, Guigou M, Pellegrino A, Bernardo A, Calviño A, Rivas F, Batista S (2012) Extracellular enzymes produced by microorganisms isolated from maritime Antarctica. World J Microbiol Biotechnol 28:2249-2256

López-Martínez R, Manzano-Gayosso P, Mier T, Méndez-Tovar LJ, HernándezHernández F (1994) Exoenzymes of dermatophytes isolated from acute and chronic tinea. Rev Latinoam Microbiol 36:17-20

Madariaga MG, Tenorio A, Proia L (2003) Trichosporon inkin peritonitis treated with caspofungin. J Clin Microbiol 41:5827-5829

Melville PA, Benites NR, Ruz-Perez M, Yokoya E (2011) Proteinase and phospholipase activities and development at different temperatures of yeasts isolated from bovine milk. J Dairy Res 78:385-390

Menezes EA, Marinho JAS, Angelo MRF, Cunha MCSO, Cunha FA, VasconcelosJúnior AA (2012) Isolation and antifungal susceptibility testing of Trichosporon asahii in Ceará, Brazil. Rev Inst Med Trop Sao Paulo 54:1-3

Muhsin TM, Aubaid AH, Al-Duboon H (1997) Extracellular enzyme activities of dermathophytes and yeast isolates on solid media. Mycoses 40:465-469

Naglik J, Albrecht A, Bader O, Hube B (2004) Candida albicans proteinases and host/pathogen interactions. Cell Microbiol 6:915-926

Nahass GT, Rosemberg SP, Leonardi CL, Penneys NS (1993) Disseminated infection with Trichosporon beigelii. Report of a case and review of the cutaneous and histologic manifestations. Arch Dermatol 129:1020-1023

Nucci M, Queiroz-Telles F, Tobón AM, Restrepo A, Colombo AL (2010) Epidemiology of opportunistic fungal infections in Latin America. Clin Infect Dis 51:561-570

Pagano L, Caira M, Candoni A, Offidani M, Fianchi L, Martino B, Pastore D, Picard M, Bonini A, Chierichini A, Fanci R, Caramatti C, Invernizzi R, Mattei D, Mitra ME, Melillo L, Aversa F, Van Lint MT, Falcucci P, Valentini CG, Girmenia C,
Nosari A (2006) The epidemiology of fungal infections in patients with hematologic malignancies: the SEIFEM-2004 study. Haematologicaac 91:1068-1075

Pagnocca FC, Lagaspe MFC, Rodrigues A, Ruivo CCC, Nagamoto NS, Bacci M Jr, Forti LC (2010) Yeasts isolated from a fungus-growing ant nest, including the description of Trichosporon chiarelli sp. nov., an anamorphic basidiomycetous yeast. Int J Syst Evol Microbiol 60:1454-1459

Price MF, Wilkinson ID, Gentry LO (1982) Plate method for detection of fosfolipase activity in Candida albicans. Sabouraudia 20:7-14

Ran Y, Yoshike T, Ogawa H (1993) Lipase of M. furfur: some properties and their relationship to cell growth. J Med Vet Mycol 31:77-85

Rodriguez-Tudela J, Diaz-Guerra TM, Mellado E, Casso V, Tapia C, Perkins A, Gómes-Lopez A, Rodero L, Cuenca-Estrella M (2005) Susceptibility patterns and molecular identification of Trichosporon species. Antimicrob Agents Chemother 49:4026-4034

Ruchel R, Tegeler R, Trost M (1982) A comparison of secretory proteinases from different strains of Candida albicans. Sabouraudia 20:233-244

Silvestre-Junior AM (2009) Sistemática molecular de Trichosporon spp. Baseada em genes ribossomais e sua correlação com fatores de virulência e epidemiologia, Thesis, Universidade Federal de São Paulo - UNIFESP

Sun W, Su J, Xu S, Yan D (2012) Trichosporon asahii causing nosocomial urinary tract infections in intensive care unit patients: genotypes, virulence factors and antifungal susceptibility testing. J Med Microbiol 61:1750-1757

Teichert U, Mechler B, Muller H, Wolf D (1989) Lysosomal (vacuolar) proteinases of yeast are essential catalysts for protein degradation, differentiation, and cell survival. J Biol Chem 264:16037-16045

Tosta CE (2001) Coevolutionary networks: a novel approach to understanding the relationships of humans with the infectious agants. Mem Inst Oswaldo Cruz 96:415-425

Walsh TJ, Melcher GP, Lee JW, Pizzo PA (1993) Infectious due to Trichosporon species: new concepts in mycology, pathogenesis, diagnosis and treatment. Curr Top Med Mycol 5:79-113

Zuben CJV (1997) Implicações da agregação espacial de parasitas para a dinâmica populacional na interação hospedeiro-parasita. Rev Saude Publica 31:523-530

\section{doi:10.1186/2193-1801-3-377}

Cite this article as: Bentubo and Gompertz: Effects of temperature and incubation time on the in vitro expression of proteases, phospholipases, lipases and DNases by different species of Trichosporon. SpringerPlus 2014 3:377.

\section{Submit your manuscript to a SpringerOpen ${ }^{\circ}$ journal and benefit from:}

- Convenient online submission

- Rigorous peer review

- Immediate publication on acceptance

- Open access: articles freely available online

- High visibility within the field

- Retaining the copyright to your article

Submit your next manuscript at springeropen.com 